\title{
Developmental Plasticity, Genetic Differentiation, and Hypoxia-induced Trade-offs in an African Cichlid Fish
}

\author{
Lauren Chapman*, ${ }^{1,2}$, James Albert ${ }^{3}$ and Frietson Galis ${ }^{4}$ \\ ${ }^{I}$ Department of Biology, McGill University, Canada \\ ${ }^{2}$ Wildlife Conservation Society, New York, NY, USA \\ ${ }^{3}$ Department of Biology, University of Louisiana, USA \\ ${ }^{4}$ Institute of Biology, Leiden University, The Netherlands
}

\begin{abstract}
In this study we explore the possible role of phenotypic plasticity in the process of adaptation and evolutionary change in the African cichlid Pseudocrenilabrus multicolor victoriae. Parental fish were collected from a hypoxic swamp, a lake ecotone, and a river in Uganda. Broods (F1) were split and grown under hypoxia or normoxia. We measured morphological parameters of the gill apparatus, structural elements surrounding the gills, brain mass, and body shape. Most traits showed substantial plasticity in response to the rearing environment. Population effects were evident for the gill apparatus, surrounding elements, body shape, and brain size; however, brain size was the only trait to exhibit variation in plasticity among populations; fish of swamp origin showed no plasticity and fish of river and lake origin exhibited smaller brain size under hypoxia. We interpret these patterns as consistent with genetic assimilation via canalization (brain) or via a shift in the norm of reaction (other traits).
\end{abstract}

Keywords: Phenotypic plasticity, genetic assimilation, Cichlidae, hypoxia.

\section{INTRODUCTION}

For more than a century there has been considerable enthusiasm among evolutionary biologists for the hypothesis that phenotypic plasticity facilitates evolutionary change by allowing the survival of populations in a different environment, followed by a slower evolutionary response as a result of selection for a better adaptedness to the changed environment [e.g., 1-16]. Hence, phenotypic plasticity is hypothesized to smooth the fitness landscape facilitating evolutionary transitions among alternative phenotypes $[17,18]$.

The process by which an environmentally induced phenotypic response comes under genotypic control is often called genetic assimilation [6], but has also been called organic selection [1-4], autonomization [5], the Baldwin effect [19], or genetic accommodation [13]. These concepts are very similar (see e.g., $[7,8,20,21]$ for discussions). The term genetic assimilation was meant to be interpreted in the broadest sense by Waddington [7], encompassing the organic selection of Baldwin, Morgan, and Osborn (i.e. the Baldwin effect, which supposes that the genetic changes occur by chance mutations, rather than by selection for already existing genetic variation) and, not being limited to canalization, as in his own experiments. Genetic assimilation can thus consist of canalization if the variation of characters becomes reduced, or a shift in the norm of reaction, as occurs when the mean trait values change without a change in the level of plasticity $[12,16,22]$.

*Address correspondence to this author at the Department of Biology, McGill University, Canada; E-mail: lauren.chapman@mcgill.ca

\section{Role of Genetic Assimilation in Evolutionary Processes Contested}

A number of studies have provided empirical support for the process of genetic assimilation (see review in [23]); however direct evidence is relatively scarce. As Matsuda [8] and Hall [10] point out, it is very difficult to prove in nature that genetic changes that have taken place were preceded by similar plastic changes. In fact, this scarcity of evidence has led several evolutionary biologists to propose that genetic assimilation is not an important process in evolution [19, 2426]. Thus, the role of phenotypic plasticity in evolution is controversial, even though models have shown rather convincingly that plasticity will sometimes constrain and sometimes facilitate evolutionary changes, depending on the shape of the fitness landscape (e.g., [16, 17, 27, 28], see also [29]). The shape of the fitness landscape depends on a complex interplay of factors. Highly important factors are the quality and costs of the plastic and evolutionary responses and the stability of the environment. For instance, if the plastic response is small, or non-adaptive, and there is a large amount of heritable phenotypic variation present for relevant parameters, a quick evolutionary response is expected with a small and perhaps negligible role for plasticity. On the other hand, if there is a highly adaptive plastic response, plasticity may provide the phenotypic variation that would otherwise be provided by genetic changes (at a slower rate) and, hence evolutionary changes are not expected $[27,28,30]$. The plastic response will mask genetic variation in relevant parameters. However, if the plastic response does not mask all the differences in fitness between individuals, an evolutionary response is expected. Interestingly, plasticity is in particular predicted to facilitate evolutionary changes if there is strong 
directional selection (accelerating curves in the fitness landscape, $[16,28])$ or if there are multiple local optima in the fitness landscape, which is for instance expected when the evolutionary process is optimizing multiple objectives with a certain trade-off function (e.g. optimizing feeding and oxygen uptake, [18]).

\section{Hypoxia-Induced Trade-Offs}

For fishes, the role of trade-offs in generating or maintaining variation has been explored for only a few species and has focused primarily on trade-offs associated with trophic specialization and predation. However, alternative aquatic oxygen environments provide another source of divergent phenotypes in fishes, particularly in morphophysiological traits related to oxygen uptake and utilization [22, 31-36]. In the case of an oxygen poor environment, there may be costs associated with gill proliferation that negatively affect performance in oxygen rich environments [22]. Because of the compact head organization that characterizes teleosts, the production of large gills may affect other surrounding morphological structures that are involved in feeding or swimming (i.e., being streamlined). The consequences of functional morphological tradeoffs may limit feeding performance, swimming efficiency, or other fitnessrelated traits, and therefore contribute to the maintenance of specialized local phenotypes in the field (multiple local optima in the fitness landscape).

\section{Comparison of Populations of Pseudocrenilabrus multi- color}

Hall [10] has suggested that a test for genetic assimilation in the field could be to look for two local populations of the same species, one of which has the ancestral character state and another a derived, putative genetically assimilated character state, and then determine whether the reaction norm of the derived character lies within the reaction norm of the original character. Local populations of the African cichlid Pseudocrenilabrus multicolor victoriae (Teleostei: Cichlidae) provide a very suitable system to carry out such a test. Pseudocrenilabrus multicolor, placed phylogenetically within the riverine Haplochromini [37] has local populations in aquatic habitats with drastically different oxygen regimes including river, lake, and swamp habitats. Given the putative riverine origin of the genus, the capacity to inhabit hypoxic swamps is presumably the more derived character state regarding capacity for oxygen uptake; whereas tolerance for normoxia in river and lake habitats is presumably the putative ancestral character state. In earlier studies on the developmental response to hypoxia of the cichlid $P$. multicolor victoriae [22], we compared F1s raised under hypoxic or well-oxygenated circumstances (one family, simple splitbrood experiment). The response to hypoxia was an $18 \%$ increase in gill area and $15 \%$ increase in total gill filament length. These results were found for fishes from a population that lives in an environment where oxygen conditions fluctuate seasonally and supra-annually. The capacity for plastic changes is purported to provide an adaptive response to fluctuations in environmental conditions [38, 39]. Indeed, the observed increase in the surface area for gaseous exchange in response to rearing under hypoxic conditions is expected to improve the oxygen uptake efficiency. Thus, we have evidence for a highly adaptive plastic response that may provide the phenotypic variation that would otherwise be provided by genetic changes. Changes in the structures surrounding the gills and in external body shape were also observed in response to growth under hypoxia, presumably the result of the increased space taken up by the gills and suggesting a potential cost to gill proliferation.

The identification of a system with high levels of phenotypic plasticity in several morpho-physiological traits [22] provides a valuable tool for exploring the potentially diverse roles of plasticity in the process of adaptation and evolutionary change. In this paper, we describe the results of a laboratory-rearing study to investigate the possible evolutionary role of phenotypic plasticity and functional-morphological tradeoffs in contributing to patterns of morphological diversification in the African cichlid P. multicolor victoriae. We ask the following three questions (a) do levels of plasticity differ among populations from divergent oxygen environments, (b) is there evidence for functional-morphological tradeoffs that may contribute to the maintenance of divergent phenotypes in the field and (c) is there evidence for directional selection on phenotypically plastic traits and support for genetic assimilation?

\section{MATERIALS AND METHODS}

\section{Study Site and Species}

Pseudocrenilabrus multicolor victoriae Schoeller 1903 (Seegers [40]) is a small (maximum total length $\approx 8 \mathrm{~cm}$ ) cichlid fish found in the Nile river system and the Lake Victoria basin [41, 42]. This species occupies a wide range of habitats including fast-flowing rivers, intermittent streams, wetland ecotonal regions at lake margins, and dense wetlands [43-45]. Where it occurs in dense Miscanthidium and papyrus swamps, it is often the dominant fish species with respect to numbers of individuals and biomass [32, 46]. Like all haplochromine cichlids, $P$. multicolor is a mouth brooder; the eggs and developing larvae are protected in the mouth of the female. Pseudocrenilabrus multicolor feeds on a large variety of plants and animals including algae, insects, and other fishes [41, 47].

We used a lab-rearing study to detect morphological plasticity in response to alternative oxygen environments, and to ask whether plasticity varies among populations. We reared fish from multiple families of three populations under hypoxia and normoxia. The first population was collected from a dense hypoxic wetland, the Lwamunda Swamp that surrounds Lake Nabugabo, Uganda (31 ${ }^{\circ} 50$ 'E and $31^{\circ} 56$ '30'E to $0^{\circ} 20^{\prime} \mathrm{S}$ and $0^{\circ} 25 ' 5$ 'S). Chapman et al. [33] reported a monthly average dissolved oxygen concentration (DO) in a swamp lagoon of $1.5 \mathrm{mg} \mathrm{l}^{-1}(\approx 25 \mathrm{~mm} \mathrm{Hg})$ during the early morning and $1.8 \mathrm{mg} \mathrm{l}^{-1}(\approx 33 \mathrm{~mm} \mathrm{Hg})$ during the early afternoon. The second site was a well-oxygenated ecotonal habitat in the nearby Lake Kayanja where DO averages $6.07 \mathrm{mg} \mathrm{l}^{-1}$ [22]. The third site was located in the Mpanga River in western Uganda $\left(0^{\circ} 25^{\prime} \mathrm{N}\right.$ and $\left.23^{\circ} 22^{\prime} \mathrm{E}\right)$ where DO averages $4.3 \mathrm{mg} \mathrm{l}^{-1}(\approx 72 \mathrm{~mm} \mathrm{Hg}$, [33]), but fluctuates both seasonally due to seasonal rains and flushing of a large upstream wetlands (monthly range $=2.2$ to $5.7 \mathrm{mg} \mathrm{l}^{-1}$ ), and on a supra-annual basis due to flooding of adjacent woodland. The Mpanga River site is located $>150 \mathrm{~km}$ west of the Nabugabo system and joins the westward flowing section of the Katonga River feeding into Lake George. The entire Ka- 
tonga River at one time flowed to the west, but it direction has been reversed by uplifting; and now it drains primarily to the east into Lake Victoria. In the Katonga River valley water flows in both directions from a swampy watershed, and may maintain a contemporary link between the Victoria and the Edward/George systems.

Recently, the population structure of $P$. multicolor was examined from 10 sites in 4 regions of Uganda (including the Mpanga River and the Lake Nabugabo region) using mitochondrial DNA and microsatellites [48]. Results based on analyses of neutral markers indicated that geographical separation influences population structure. However, the most common haplotype (Type A) was found in fish from both the Mpanga River and Nabugabo regions. This suggests that the fish from the three populations sampled in our study may have originated from one source population, in which this haplotype was common, although genotypes within the Mpanga region tended to form one genetic cluster and genotypes within the Nabugabo region tended to form one genetic cluster [48].

Adult fish were live captured using metal minnow traps and live-transferred to the Department of Zoology at the University of Florida for the rearing experiment. Stock were held under normoxic conditions under a 12:12 photoperiod, and maintained on flake food.

\section{Lab-Rearing Experiment}

We carried out a lab-rearing study to test for morphological plasticity in response to alternative oxygen environments, and to ask whether plasticity varies among populations. F1 generation fish from the three populations of $P$. multicolor [Lwamunda Swamp (low oxygen), Lake Kayanja (high oxygen), Mpanga River (fluctuating oxygen)] were grown under extreme hypoxia $\left(\sim 1.3 \mathrm{mg} \mathrm{l}^{-1}\right)$ and normoxia $\left(\sim 7.6 \mathrm{mg} \mathrm{l}^{-1}\right)$. Broods from six families per population were reared in the experiment to provide family level replication; the number of families was limited due to the complexity of measuring key target traits (gill metrics, trophic musculature) required to examine potential tradeoffs. Adult brooding pairs were held in separate, normoxic aquaria until the young were completely released from the female's mouth. When a brood was released from a female, each brood was divided into two groups and randomly allocated to one of thirty-six 76-L aquaria (half maintained at normoxia and half under hypoxic conditions). Fish were introduced into the experiment over a 7 -week period due to variation in spawning events. A small algae-eating Hypostomus plecostomus catfish was introduced into each tank to control algal growth. Broods were cropped randomly to an average of 8 young per aquaria after 3 months (from the time of entry into the experiment). Based on earlier studies in our lab, this density allows fish to grow to a size reflective of some field populations. Fish were harvested after a minimum of 1 year; generally normoxia-reared fish were harvested first, to facilitate overlap in body size between treatments for analyses of allometric traits. Before fish were harvested, the resting routine metabolic rate and critical oxygen tension of each fish was measured (not reported here), a process requiring approximately 6 months. Fish were returned to their rearing environment for at least 1 week before being euthanized with MS222 (1 g per litre buffered with $4 \mathrm{~g}$ of sodium bicarbonate).
The dissolved oxygen, DO, of the experimental tanks was controlled by pulsing nitrogen through a diffuser in each aquarium to reduce DO levels. DO measurements were collected daily to monitor and regulate DO levels. DO was averaged for each tank to produce a mean and inter-tank error estimate $\left(n=11,824\right.$ measures); DO averaged $7.6 \pm 0.023 \mathrm{mg} \mathrm{l}^{-}$ ${ }^{1}$ in the normoxic tanks and $1.3 \pm 0.025 \mathrm{mg} \mathrm{l}^{-1}$ ) in the hypoxic aquaria. Underwater filtration was achieved by a Mag drive pump (with sponge biofiltration) modified by $3 / 4$-inch tubing to ensure adequate circulation. Aquaria were held at $25{ }^{\circ} \mathrm{C}$ (average for normoxia $=24.9 \pm 0.029{ }^{\circ} \mathrm{C}$; average for hypoxia $=25.1 \pm 0.05{ }^{\circ} \mathrm{C}$ ) and exposed to a $12 / 12$ photoperiod. Fish were fed once per day on fry bites (until 3 months old) and then on Tetramin food flakes.

We measured morphological characters of four different categories: the gill apparatus, structural elements surrounding the gills, brain mass, and outer shape characters. For characters requiring careful dissection (gills, surrounding elements, brain mass) we targeted one male from each family per population and treatment. This minimized variation induced by brooding in females and produced an average sample size of 6 fish per population per treatment. One tank was removed due to disease and one tank had no males. For gill metrics, we analyzed only males greater than $2.2 \mathrm{~g}$ in mass. To increase our sample to an average of 6 for some traits and to increase overlap in size ranges, we sampled additional males (gills) and some small non-brooding females or males (brains), but no more than two fish were used from any one tank. For external body shape traits, we measured multiple fish per family within each population and treatment, permitting us to test for family level variation and a family $\mathrm{x}$ treatment interaction, and to explore gender effects, with an average sample size of 35 fish per population per treatment. We measured females before or between brooding cycles, not during the brooding period.

\section{Gill Parameters}

We measured a series of gill parameters on the right side of the branchial basket. We focused on five gill measurements that represent the size and shape of the filamentous part of gills, because we were interested in the way in which proliferation of the gills may affect nearby structures. Characters measured included: total gill filament length (TGFL), average filament length (AFL), total gill filament number (TFN), total area of the hemibranchs (THA), and total perimeter of the hemibranchs (THP, Fig. (2) in Langerhans et al. [36]). We selected TGFL rather than another commonly measured parameter, gill surface area, because it is more likely to reflect spatial constraints of large gills, and because it has been well-documented that $P$. multicolor from hypoxic waters has a larger TGFL than fish from well-oxygenated sites [22, 33]. Further, previous studies have found that for $P$. multicolor and two other fish species, populations with larger TGFL are characterized by a larger gill surface area (P. multicolor [22], Poecilia latipinna, Timmerman and Chapman [49], Astatoreochromis alluaudi [34]). For this study, we corroborated this pattern by measuring total gill surface area (TGSA) for two fish per population per treatment. Sample size for gill surface area was limited by the complexity of measures involved in accurate estimate of TGSA. 
To quantify TGFL, each of the four gill arches from the left side of the branchial basket was separated and laid flat on a microscope slide. For each hemibranch, the length of every $5^{\text {th }}$ gill filament was measured. Two successive measurements were averaged to estimate length of intermediate filaments. Filament lengths were summed for the eight hemibranchs and, assuming bilateral symmetry, were multiplied by 2 to yield an estimate of TGFL. Average filament length (AFL) was calculated as the mean of the length of all measured filaments. The total number of filaments was counted for each hemibranch on one side of the fish and multiplied by 2 to produce an estimate of the total number of filaments on the branchial basket (TFN). To estimate hemibranch area, we digitized the area of the gill filaments on the 8 hemibranchs on 1 side of the fish. This area was multiplied by 2 to produce an estimate of the total hemibranch area (THA, not including the bony arches). Total hemibranch perimeter (THP) was estimated as the sum of the perimeters of the 8 hemibranchs on 1 side of the fish (not including the bony arches) multiplied by 2 . Total gill surface area was measured using standard methods modified after Muir and Hughes [50] and Hughes [51] and described in Timmerman and Chapman [49] and Chapman et al. [34].

\section{Structural Elements Surrounding the Gills}

We selected a series of characters that we predicted most likely to be affected by change in gill size based on earlier studies [22]. Measurements were made of the length, height, and depth of the $\mathrm{m}$. sternohyoideus and $\mathrm{m}$. geniohyoideus. Length was measured from origin to insertion; height and depth were measured in the middle of the muscle. The formula for an ellipse ( 0.5 width $\times 0.5$ width $\times \lambda)$ was employed to estimate the cross-sectional areas of the sternohyoideus and geniohyoideus. In addition, we quantified the depth of the upper pharyngeal jaw, and the depth of the keel of the lower pharyngeal jaw as an estimate of the thickness of the pharyngeal jaws.

\section{Brain Mass}

Methods for assessing relative brain weight follow Albert et al. [52]. Briefly, whole brains (excluding adenohypophesis) were removed from formalin fixed specimens using microdissection tools under an Olympus SZX 12 dissection microscope and stripped of blood vessels and meningeal membranes. Each brain was severed from the spinal cord 1 $\mathrm{mm}$ posterior to the first spinal nerve, and all cranial nerves (including optic tract) were severed about $0.2 \mathrm{~mm}$ from the brain surface. Brains were blotted and weighed (wet mass) to $0.01 \mathrm{~g}$ on an analytical balance. The accuracy of a brain weighing $1.0 \mathrm{~g}$ from 10 repeated measurements was $\pm 0.015 \mathrm{~g}$.

\section{External Body Shape Traits}

For external body shape, we measured a series of linear distances between landmark points that may reflect gill proliferation under hypoxic conditions and shape tradeoffs between low- and high-oxygen habitats. Preserved specimens were placed on a laminated grid mounted on a level platform. We captured a lateral image of the right side of each fish (resolution of $0.05 \mathrm{~mm} /$ pixel) using a digital camera (Nikon Coolpix 4500) mounted on a tripod, and linear measures were derived from the photos using Motic $\odot ~ 2000$. Fol- lowing Barel et al. [53], we quantified standard length, head length, eye depth, and body depth. The depth of the epaxial muscle was estimated as the linear measure from the anterior origin of the dorsal fin to the point of maximum curvature on the edge of the operculum. Head width was quantified from a dorsal view image, across the operculum at the maximum outcropping of the gills. All measures were done using MOTIC software (Motic Images 2000).

\section{Statistical Analyses}

For the gill metrics and surrounding structural elements, multivariate analysis of covariance was used to look at the effects of population, treatment (high and low oxygen), and their interaction on suites of traits. The homogeneity of slopes assumption was tested by looking at the interaction between the covariate and the main effects. For brain mass, we used a univariate analysis of covariance to detect effects of population, treatment, and their interaction. For brain mass, the interaction term was significant, so we reran the analysis for each population separately. For external body shape characters for which sample size was much larger, we also used MANCOVA, but included family effects. Family was nested within population, and we tested for the effects of family and the family $x$ treatment interaction. A significant family $x$ treatment interaction indicates that families respond differently to the treatment and thus that plasticity has a genetic component. However, in our design family effects are confounded by tank (microenvironmental) effects, and thus should be treated with caution

If the main MANCOVA effects were significant, univariate ANCOVA was used to explore the role of individual traits. It should be noted that the relative magnitude of the P values for each trait are of interest in these analyses, because the multivariate test establishes an a priori significance for the group of traits [54].

We performed discriminant function analyses (DFA) to classify fish by treatment and population, providing a metric of the magnitude of particular effects. The first DFA evaluated the magnitude of morphological variation induced by treatment effects (plasticity); the second DFA examined the magnitude of population effects independent of plastic variation. We also performed DFA to classify fish by population $\mathrm{x}$ treatment combinations (six groups). Prior probabilities for all DFA analyses were computed from group sizes. For the DFA, trait values were size-adjusted using the commonwithin-group slope generated from ANCOVA for each trait, after removal of the non-significant interaction term. Standardized trait values were calculated as $\mathrm{T}_{\text {std }}=\mathrm{T}_{\text {obs }}$ (Average $\left.\mathrm{S}) / \mathrm{S}_{\mathrm{obs}}\right)^{\mathrm{b}}$, where $\mathrm{S}$ is the average size (mass for gill metrics and standard length for surrounding structural elements) of the fish derived from the ANCOVA (antilog value), $\mathrm{T}$ is the trait size (not log transformed), $\mathrm{S}$ is the body size (not $\log$ transformed), $\mathrm{b}$ is the common-within-group slope, and the subscripts std and obs refer to standardized and the observed measurements $[55,56]$.

\section{RESULTS}

\section{Gill Metrics}

The results of multivariate analysis of variance on gill metrics using body mass as a covariate indicated a strong effect of treatment (low vs. high oxygen, DO, P<0.001) on 
Table 1. Summary of multivariate analysis of variance (MANCOVA) tests for effects of population (swamp, lake, river) of origin, treatment (hypoxia, DO $\sim 1.3 \mathrm{mg} \mathrm{l}^{-1} v s$. normoxia, DO $\sim 7.6 \mathrm{mg} \mathrm{l}^{-1}$ ), and their interaction on gill size, surrounding structural elements (muscles, pharyngeal jaws), and brain mass for Pseudocrenilabrus multicolor. Wilks' lamda values were used to approximate $\mathrm{F}$-values for population and the interaction term. Body mass was used as the covariate for gill metrics and brain mass; standard length was used as the covariate for surrounding structural elements. All variables were $\log _{10}$ transformed

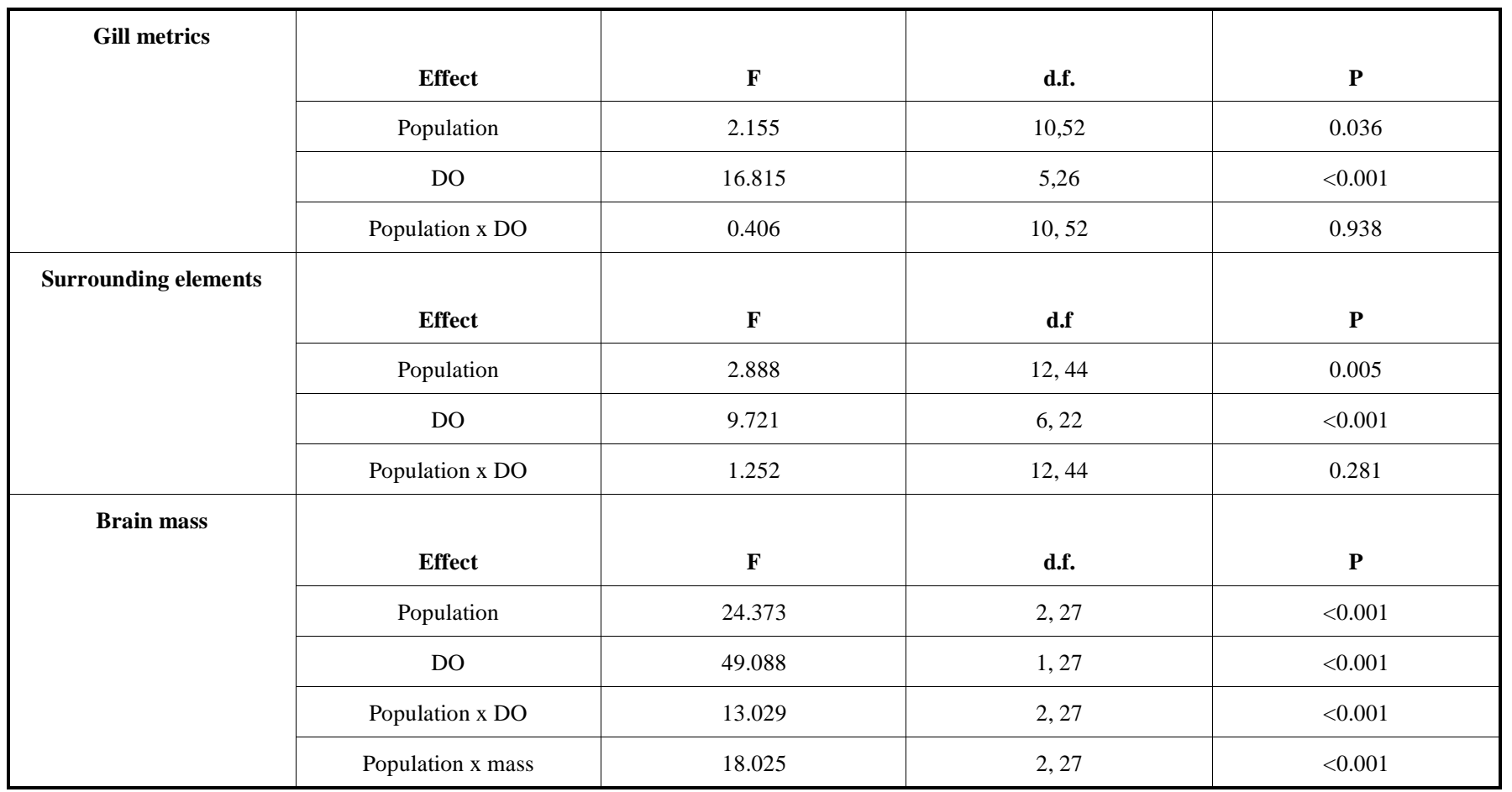

Table 2. Summary of analyses of covariance (ANCOVA) for effects of population (swamp, lake, river) of origin and treatment (hypoxia, DO $\sim 1.3 \mathrm{mg} \mathrm{l}^{-1}$ vs. normoxia, DO $\sim 7.6 \mathrm{mg} \mathrm{l}^{-1}$ ) on gill size and shape characters for Pseudocrenilabrus multicolor. There was no significant interaction term (popn $x$ treatment) for these metrics. Both gill characters and body mass (covariate) were $\log _{10}$ transformed. Values are adjusted means with their standard errors calculated from the ANCOVA analyses (sample means adjusted for a common mean body mass of $3.4 \mathrm{~g}$ and a common regression line). Antilog values of the adjusted means are presented in brackets

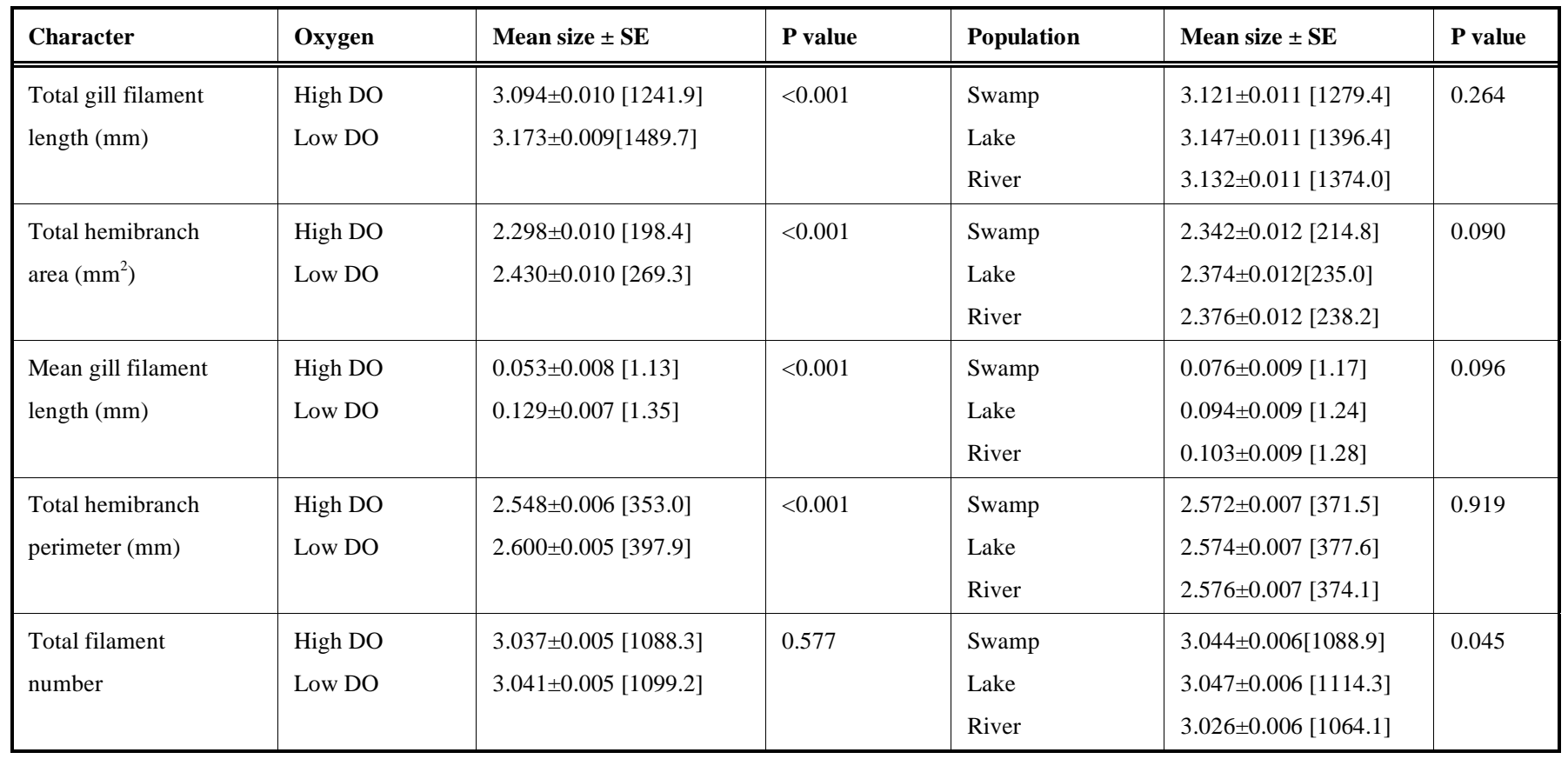



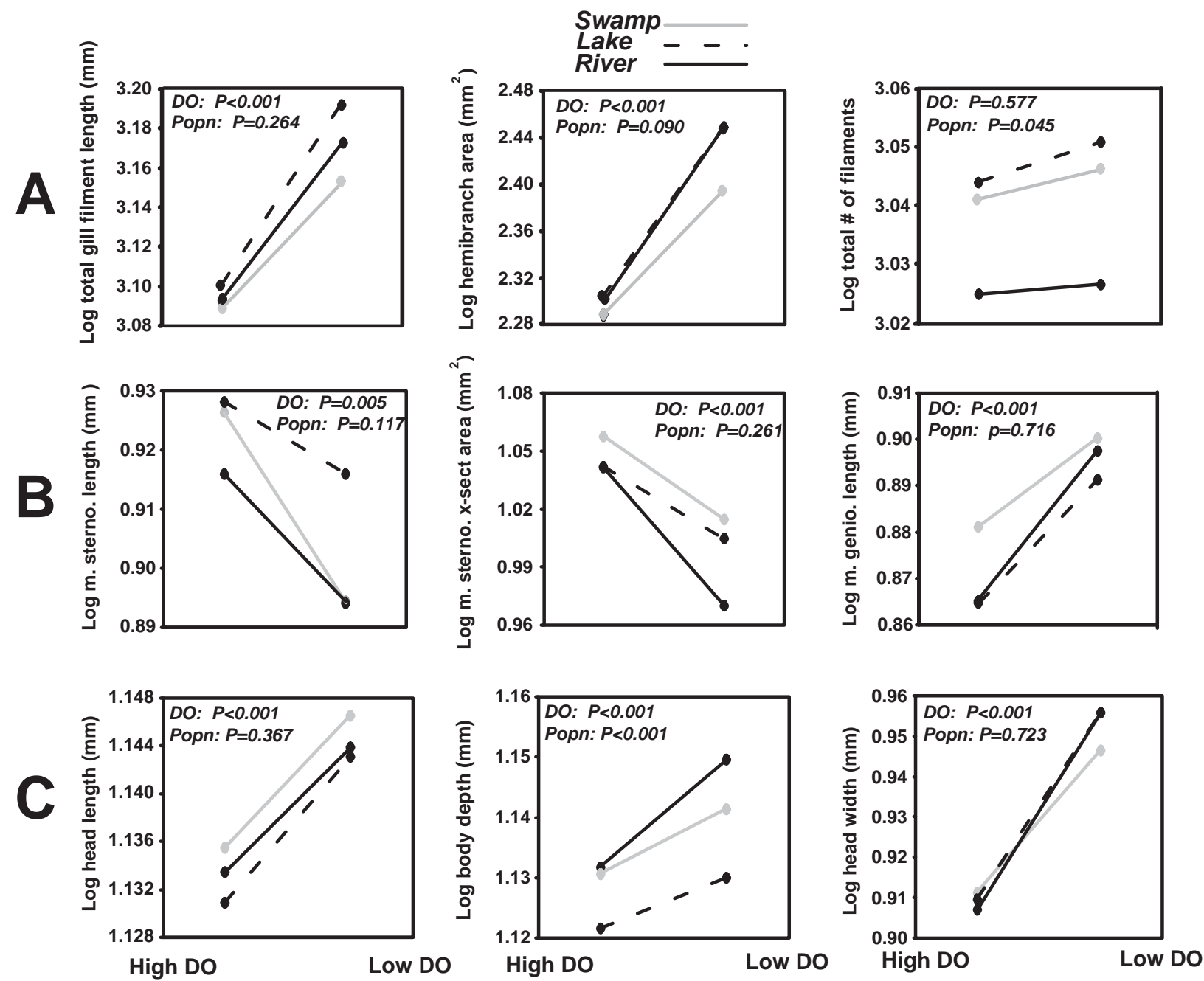

Fig. (1). Reaction norms derived from univariate ANCOVAs for (A) gill metrics, (B) surrounding structural elements, and (C) whole-body traits of F1 Pseudocrenilabrus multicolor from three populations reared under high and low dissolved oxygen (DO) conditions. Each line joins the adjusted mean value for low and high DO treatments for one population. Probability values at the top of each panel represent the DO effect and population (Popn) effect. DO x Popn interactions were not significant.

gill size, and a population effect $(\mathrm{P}=0.036)$, but no interaction between $\mathrm{DO}$ and population $(\mathrm{P}=0.938$, Table 1). The covariate (body mass) was significant $(\mathrm{P}<0.0001)$ indicating multivariate allometry.

Univariate ANOVAs indicated that the gill metrics measured, with the exception of total filament number were highly plastic; percent difference between treatments (where significant differences occurred) ranged from $11 \%$ for hemibranch perimeter to $26 \%$ for total hemibranch area (Table 2 , Fig. 1a). Population effects were weak in univariate comparisons; however, the river population showed a lower number of filaments overall, and there was a tendency towards smaller gill size (hemibranch area, average filament length, Table 2, Fig. 1a) in the swamp population than in the lake and river. For all univariate comparisons, the covariate was significant $(\mathrm{P}<0.001)$, and there were no significant population $\mathrm{x}$ treatment interactions $(\mathrm{P}>0.05)$.

Discriminant function analyses indicated significant morphological differences between treatments. Based on gill metrics, our first DFA analysis classified $97.3 \%$ of the original fish into the correct treatment (low vs. high oxygen) category (Wilks' $\lambda=0.197, \mathrm{P}<0.001$ ). Thus, all populations differed in gill metrics between treatments in so similar a manner, that most fish could be correctly classified into their hypoxia environment, regardless of population. Our second DFA predicted population of origin for each fish based on gill morphology. This DFA was marginally significant (Wilks' $\lambda=0.590, \mathrm{P}=0.078$ ), and classified $70.3 \%$ of the fishes into the correct population regardless of their rearing environment; suggesting that plastic response to the DO environment has a stronger effect on gill metrics than population of origin. Our third DFA predicted group based on the combination of population and treatment and classified $70.3 \%$ of the fish in the correct category; the plot of group spread and centroids shows the stronger separation of the six groups based on treatment than on population (Wilks' $\lambda=$ $0.114, \mathrm{P}<0.001$, Fig. 2a).

In general, differences in gill metrics induced by plastic response to the rearing environment (expressed as a percent) were greater than differences between field collected specimens of $P$. multicolor from a high (Lake Kayanja) and low (Lwamunda Swamp) (Fig. 3a). For example, total gill filament length and total hemibranch area differed by $16 \%$ and $26 \%$, respectively, for fish reared under hypoxic and normoxic condition in the lab. In a comparison of these same 

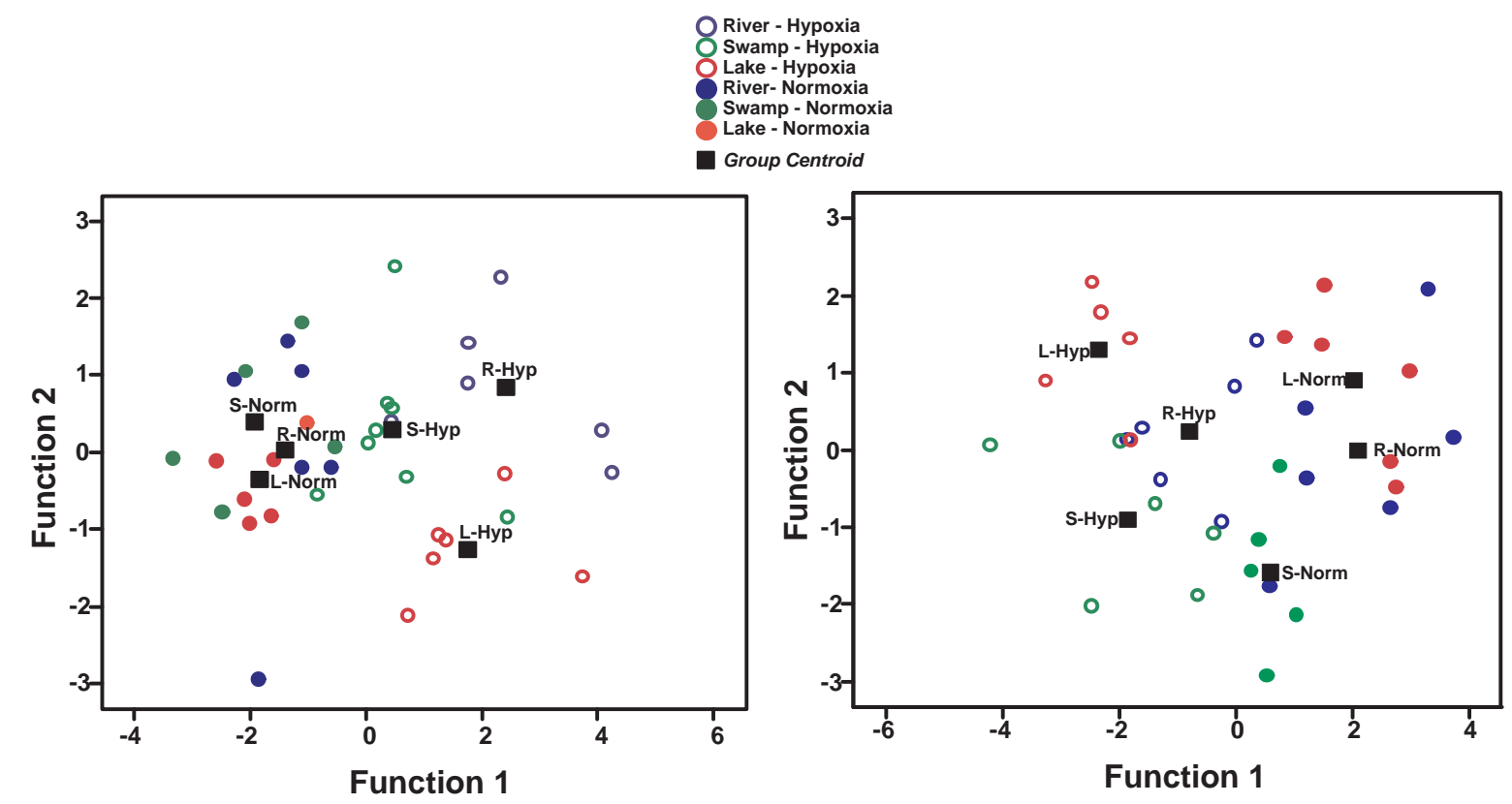

Fig. (2). Discriminant Function biplot based on the first two significant functions for six groups of Pseudocrenilabrus multicolor (two treatments, three populations). Characters entered into the model included (a) standardized gill metrics, and (b) standardized surrounding structural elements. Function 1 clearly separates species from high- and low-oxygen waters. Dark squares refer to centroids of each group (each group representing one population/one treatment).

traits in parental stock collected from Lake Kayanja and the Lwamunda Swamp we have found differences of $12 \%$ and $15 \%$, respectively (Chapman, Galis, and Albert, unpubl. data).

Total gill surface area was measured for 2 fish per population per treatment. Although sample size was low for this analysis, due to the complexity of the measures, there was a strong treatment effect $(\mathrm{F}=27.050, \mathrm{P}=0.002$, Fig. 4), but no evidence for a population effect $(\mathrm{F}=0.806, \mathrm{P}=0.490)$, or an interaction $(\mathrm{F}=0.952, \mathrm{P}=0.437)$. These data suggest that fish of swamp origin may have smaller spatial requirements for gills (e.g., smaller hemibranch area), but a similar surface area to those of the river and lake F1s; however, sample size argues for a cautious interpretation.

\section{Structural Elements Surrounding the Gills}

The results of MANCOVA on structural elements surrounding the gills (muscles, pharyngeal jaws) indicated a strong effect of DO $(\mathrm{P}<0.001)$, a population effect $(\mathrm{P}=0.005)$, but no interaction between $\mathrm{DO}$ and population $(\mathrm{P}=0.281$, Table 1). The covariate (standard length) was significant $(\mathrm{P}<0.0001)$. Univariate ANOVAs on the surrounding structural metrics indicated significant developmental plasticity in the both the geniohyoideus and sternohyoideus muscles. The length of the geniohyoideus muscle was $6 \%$ longer in the hypoxic treatment across populations (Table $\mathbf{3}$, Fig. 1b); while both the length and cross sectional area of the sternohyoideus muscle were smaller in fish raised under hypoxia (5\% and $13 \%$, respectively). In univariate analysis, population effects were only evident in the depth of the upper pharyngeal jaw, which was smaller in the fish of swamp origin (Table 3, Fig. 1b). For all univariate comparisons, the covariate was significant $(\mathrm{P}<0.001)$, and there was no significant population $\mathrm{x}$ treatment interaction.
Discriminant function analyses indicated significant musculoskeletal differences between treatments and among populations. Our first DFA analysis classified fish by treatment. The DFA classified $100 \%$ of the original 35 fish into the correct treatment (low vs. high oxygen) category (Wilks' $\lambda=0.272, \mathrm{P}<0.001)$. Thus, all populations differed in the surrounding musculoskeletal elements between treatments in so similar a manner, that most fish could be correctly classified into their rearing environment, regardless of population. Our second DFA predicted population of origin for each fish based on musculoskeletal features. This DFA classified $76.5 \%$ of the fish into the correct population regardless of their rearing environment (Wilks' $\lambda=0.372, \mathrm{P}=0.005$ ), suggesting that plastic response to the DO environment has a stronger effect on the structures surrounding the gills than population of origin. Our third DFA predicted group based on the combination of population and treatment and classified $85.3 \%$ of the fish in the correct category; the plot of group spread and centroids shows nice separation between high- and low-oxygen groups, but also indicates some separation among the three populations (Wilks' $\lambda=0.051$, $\mathrm{P}<0.001$, Fig. 2b).

Differences (expressed as a percent) in surrounding structural elements induced by plastic response to the rearing environment were generally similar to the differences between field collected fish from Lake Kayanja (high DO) and the Lwamunda Swamp (low DO) with the exception of the depth of the lower pharyngeal jaw (Fig. 3b).

\section{Brain Mass}

ANCOVA indicated heterogeneity in the slopes of the bilogarithmic relationship between brain and body mass among populations. We therefore conducted the analysis with and without the interaction term of body mass and population and examined significance of the effects. Results 
Lab - \% difference between low and high DO treatment (all 3 lab populations combined)

Field - \% difference between field-collected specimens

- from Lwamunda (low DO) and Kayanja (high DO)

* Significant difference between high and low treatments or high and low-DO field popns

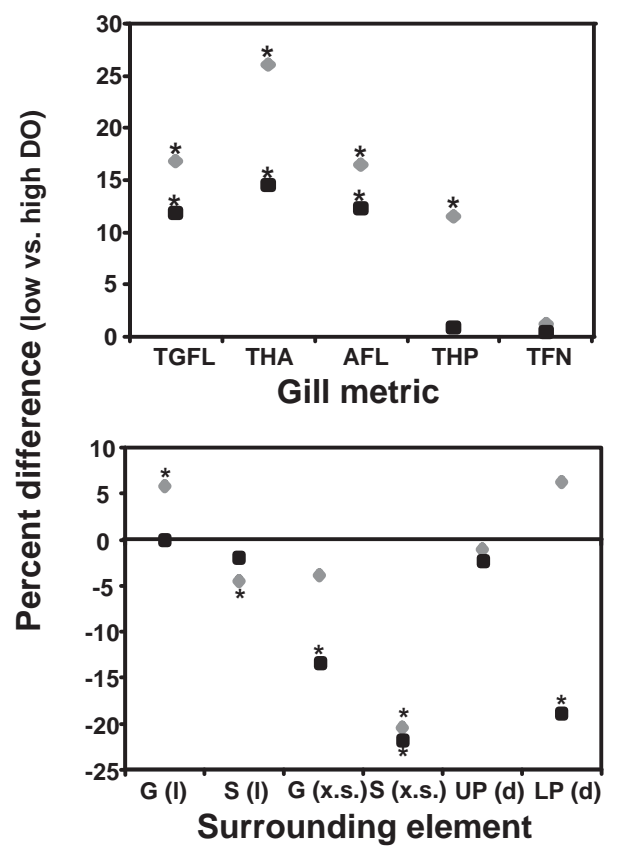

Fig. (3). The percent difference between gill metrics and surrounding structural elements for $P$. multicolor reared under high and low dissolved oxygen (DO) (=Lab, this study) and from a high vs. low field population (Lwamunda Swamp vs Lake Kayanja, Chapman, Galis, \& Albert, unpubl. data). TGFL - total gill filament length; THA - total hemibranch area; AFL - average filament length; THP - total hemibranch perimeter; TFN - total number of filaments; $\mathrm{G}(\mathrm{l})$ - length of the geniohyoideus muscle; G(x.s.) - cross-sectional area of the geniohyoideus muscle; $S(1)$ - length of the sternohyoideus muscles; S(x.s.) - cross-sectional area of the sternohyoideus muscles, UP (d) - depth of the upper pharyngeal jaw; LP(d) - depth of the lower pharyngeal jaw measured at the keel.

were highly similar. Effects of population, treatment, and their interaction were all significant (Table 1). Results were also similar when only fish greater than $2 \mathrm{~g}$ were analyzed. ANCOVAs conducted on each population separately indicated homogeneous slopes between treatments within each population. Relative brain size was smaller in fish raised under hypoxia in both the river and lake populations (Lake: $\mathrm{F}=16.92$, $\mathrm{P}=0.002$; River: $\mathrm{F}=44.01$, $\mathrm{P}<0.001$, Fig. 5). However, for fish of swamp origin, there was no effect of treatment $(\mathrm{F}=0.086, \mathrm{P}=0.776)$.

Differences in relative brain mass induced by the rearing environment averaged $17 \%$ for the two populations that exhibited a significant treatment response. This is a slightly smaller difference than $P$. multicolor collected from field high- and low-DO field populations (21\%, Chapman, Galis, and Albert, unpubl. data).

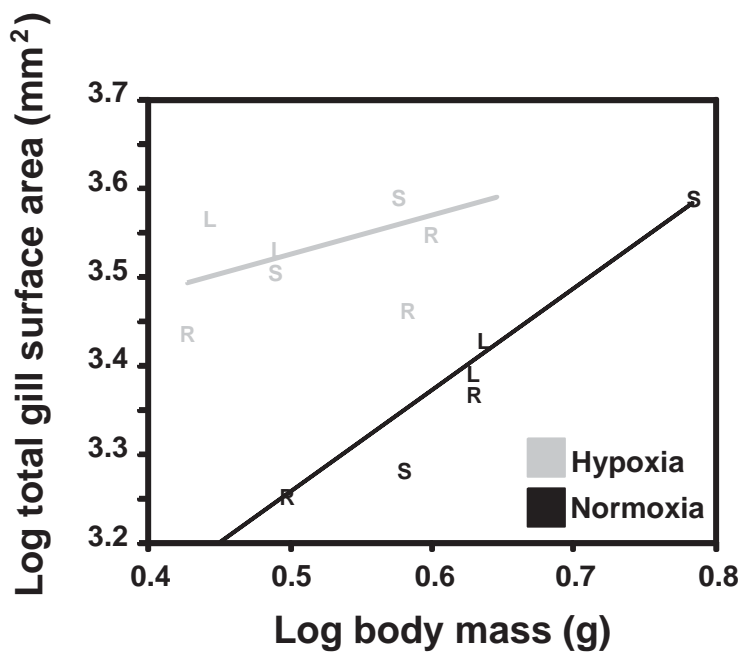

Fig. (4). Bilogarithmic relationships between total gill surface area and body mass for F1 Pseudcrenilabrus multicolor reared under high and low DO conditions. $\mathrm{S}=$ swamp; $\mathrm{L}=$ lake; $\mathrm{R}=$ river.

\section{External Body Shape}

The results of MANCOVA on five external body shape traits showed a strong treatment effect of $\mathrm{DO}(\mathrm{P}<0.001)$, a population effect $(\mathrm{P}=0.005)$, but no interaction between $\mathrm{DO}$ and population $(\mathrm{P}=0.584$, Table 4$)$. The covariate (standard length) was significant $(\mathrm{P}<0.001)$. Because we had replication within families for these characters, we also tested for a treatment by family interaction. Both family and the family (popn) x treatment interaction were significant (Table 1). A significant family (popn) $\mathrm{x}$ treatment interaction indicates that families respond differently to the treatment, and thus that plasticity has a genetic component. However, in our design family effects are confounded by tank (microenvironmental) effects and thus may reflect either or both.

In our analyses of external body shape traits, we also tested for gender effects because we measured multiple fish per family. The sex ratio was skewed in the hypoxia treatment (hypoxia: $71 \%$ females; normoxia: $54 \%$ females). Because of the large of number factors (treatment, population, family, and gender), we did not include all factors in one model. Rather, we reran the MANCOVA analysis for females only (the larger sample size) for families with greater than six fish. Results were similar as for males and females combined, with a strong effect of treatment $(\mathrm{F}=24.492$, $\mathrm{P}<0.001)$, and effect of population $(\mathrm{F}=3.773, \mathrm{P}<0.001)$, and no treatment $x$ population interaction $(\mathrm{F}=1.362, \mathrm{P}=0.204)$. The family(popn) $\mathrm{x}$ treatment interaction was also significant $(\mathrm{F}=1.959, \mathrm{P}=0.002)$.

Univariate ANOVAs indicated that the five external body shape traits measured were highly plastic. Head length, body depth, head width, and eye depth were all significantly larger in fish reared under hypoxia than in fish reared under normoxia (Table 5, Fig. 1c). Percent difference between treatments ranged from $3 \%$ for average head length to $10 \%$ for head width (Table 5). The mean depth of the epaxial muscle was $4 \%$ smaller in fish raised under hypoxic conditions 
Table 3. Summary of analyses of covariance (ANCOVA for effects of population (swamp, lake, river) of origin and treatment (hypoxia, DO $\sim 1.3 \mathrm{mg} \mathrm{l}^{-1}$ vs. normoxia, DO $\sim 7.6 \mathrm{mg} \mathrm{l}^{-1}$ on structural elements surrounding the gills for Pseudocrenilabrus multicolor. There was no significant interaction term (popn $\mathrm{x}$ treatment) for these metrics. Both structural elements and standard length (covariate) were $\log _{10}$ transformed. Values represent adjusted means with their standard errors calculated from the ANCOVA analyses (sample means adjusted for a common mean standard length of $47.2 \mathrm{~mm}$ and a common regression line). Antilog values of the adjusted means are presented in brackets

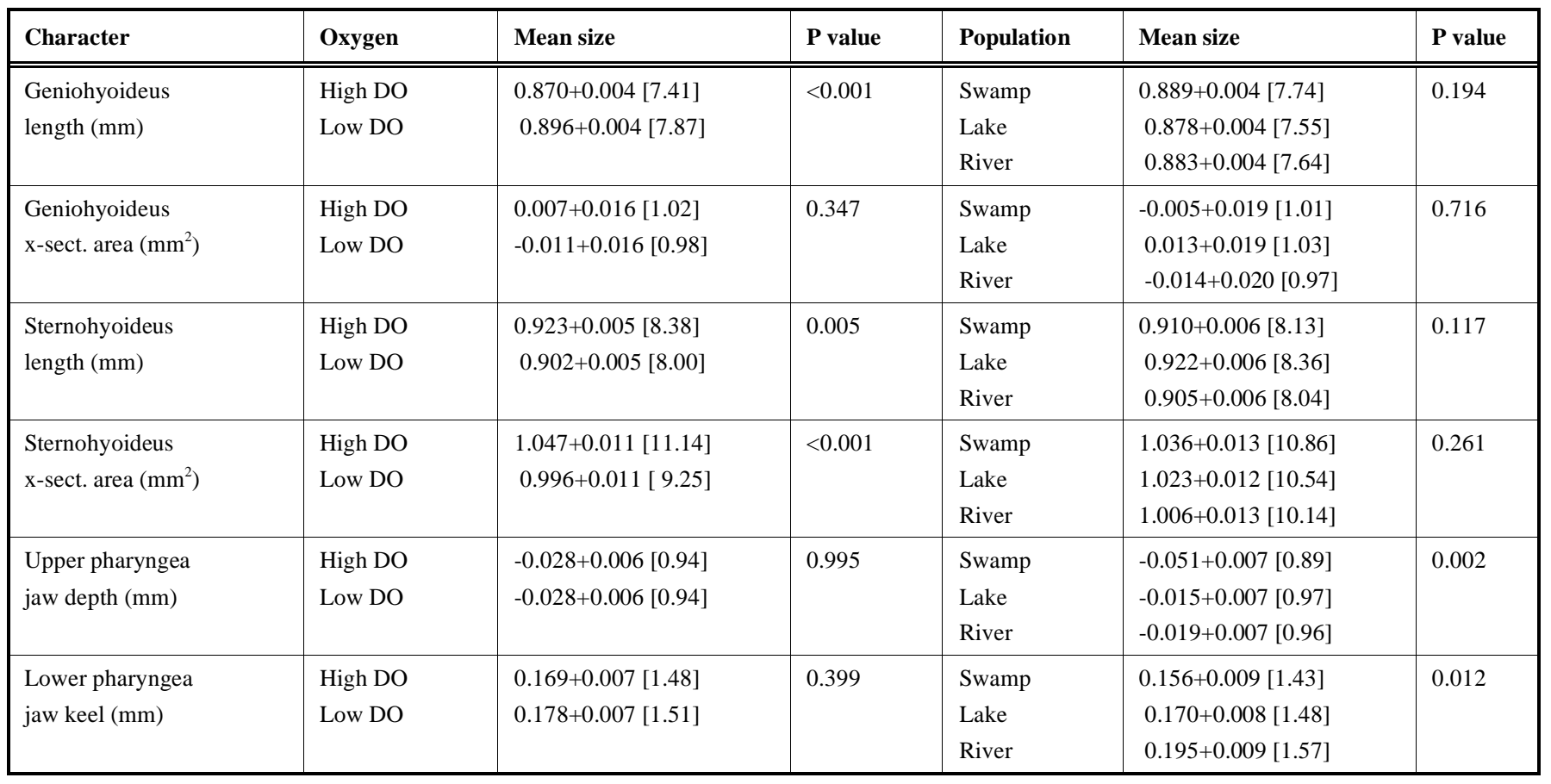
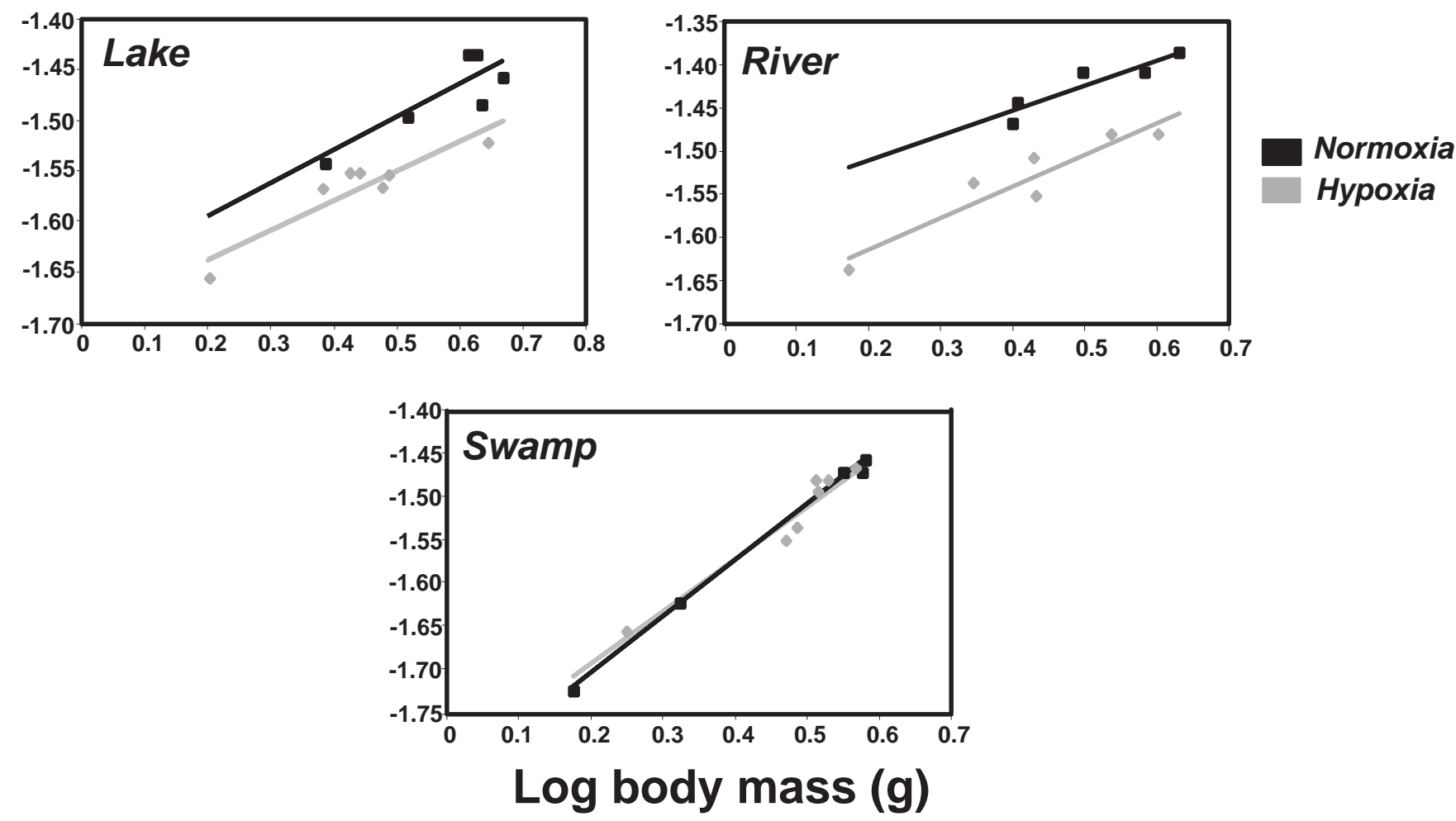

Fig. (5). Bilogarithmic relationships between brain mass and body mass for F1 Pseudcrenilabrus multicolor reared under high and low DO conditions. Slopes differed among populations, so each population is presented separately. 
Table 4. Summary of a multivariate analysis of variance (MANCOVA) test for effect of population (swamp, lake, river) of origin, treatment (hypoxia, DO $\sim 1.3 \mathrm{mg} \mathrm{I}^{-1}$ vs. normoxia, DO $\sim 7.6 \mathrm{mg} \mathrm{I}^{-1}$ ), family(population), and their interaction on 5 outer shape characters for Pseudocrenilabrus multicolor. Wilks' lamda values were used to approximate F-values for population and the interaction terms. Standard length was used as the covariate for surrounding structural elements. All variables were $\log _{10}$ transformed. $\mathrm{N}=\mathbf{2 1 1}$ fish

\begin{tabular}{|l|c|c|c|c|}
\hline Outer shape traits & Effect & F & d.f & P \\
\hline \hline \multirow{3}{*}{$\begin{array}{l}\text { Population } \\
\text { DO }\end{array}$} & 4.695 & 10,344 & $<0.001$ \\
\cline { 2 - 5 } & Population x DO & 46.853 & 5,172 & $<0.001$ \\
\cline { 2 - 5 } & Family(Popn) & 0.846 & 10,344 & 70,823 \\
\cline { 2 - 5 } & Family(Popn) x DO & 3.836 & 70,823 & $<0.001$ \\
\cline { 2 - 5 } & & 2.243 & $<0.001$ \\
\hline
\end{tabular}

Table 5. Summary of analyses of covariance (ANCOVA) for effects of population (swamp, lake, river) of origin, treatment (hypoxia, DO $\sim 1.3 \mathrm{mg} \mathrm{I}^{-1}$ vs. normoxia, DO $\sim 7.6 \mathrm{mg} \mathrm{l}^{-1}$ ) on outer shape traits for Pseudocrenilabrus multicolor. Both gill characters and standard length (covariate) were $\log _{10}$ transformed. Values represent adjusted means with their standard errors calculated from the ANCOVA analyses (sample means adjusted for a common mean standard length of $47.2 \mathrm{~mm}$ and a common regression line). Antilog values of adjusted means are presented in brackets. The ANCOVA model included effects of population, treatment, popn*treatment, family(popn), and family(popn)*treatment

\begin{tabular}{|c|c|c|c|c|c|c|}
\hline Character & Oxygen & Mean size & $P$ value & Population & Mean size & $P$ value \\
\hline $\begin{array}{l}\text { Body depth } \\
(\mathrm{mm})\end{array}$ & $\begin{array}{l}\text { High DO } \\
\text { Low DO }\end{array}$ & $\begin{array}{l}1.128 \pm 0.002[13.43] \\
1.140 \pm 0.002[13.80]\end{array}$ & $<0.001$ & $\begin{array}{l}\text { Swamp } \\
\text { Lake } \\
\text { River }\end{array}$ & $\begin{array}{l}1.136 \pm 0.002[13.68] \\
1.126 \pm 0.002[13.37] \\
1.141 \pm 0.002[13.84]\end{array}$ & $<0.001$ \\
\hline $\begin{array}{l}\text { Epaxial muscle } \\
\text { depth (mm) }\end{array}$ & $\begin{array}{l}\text { High DO } \\
\text { Low DO }\end{array}$ & $\begin{array}{c}0.732 \pm 0.003[5.40] \\
0.714 \pm 0.003[5.18]\end{array}$ & $<0.001$ & $\begin{array}{l}\text { Swamp } \\
\text { Lake } \\
\text { River }\end{array}$ & $\begin{array}{l}0.730 \pm 0.004[5.37] \\
0.710 \pm 0.003[5.13] \\
0.730 \pm 0.003[5.37]\end{array}$ & $<0.001$ \\
\hline $\begin{array}{l}\text { Head width } \\
(\mathrm{mm})\end{array}$ & $\begin{array}{l}\text { High DO } \\
\text { Low DO }\end{array}$ & $\begin{array}{c}0.909 \pm 0.003[8.11] \\
0.953 \pm 0.003[8.97]\end{array}$ & $<0.001$ & $\begin{array}{l}\text { Swamp } \\
\text { Lake } \\
\text { River }\end{array}$ & $\begin{array}{c}0.929 \pm 0.004[8.49] \\
0.933 \pm 0.003[8.57] \\
0.931 \pm 0.003[8.53]\end{array}$ & 0.723 \\
\hline $\begin{array}{l}\text { Eye } \\
\text { depth (mm) }\end{array}$ & $\begin{array}{l}\text { High DO } \\
\text { Low DO }\end{array}$ & $\begin{array}{c}0.570 \pm 0.002[3.72] \\
0.586 \pm 0.002[3.85]\end{array}$ & $<0.001$ & $\begin{array}{l}\text { Swamp } \\
\text { Lake } \\
\text { River }\end{array}$ & $\begin{array}{c}0.577 \pm 0.002[3.78] \\
0.577 \pm 0.002[3.78] \\
0.581 \pm 0.002[3.81]\end{array}$ & 0.298 \\
\hline
\end{tabular}

(Table 5). Among populations, both body depth and expaxial muscle depth were smaller in the F1s of lake origin (Table $\mathbf{5}$, Fig. 1c). For all univariate comparisons, the covariate (standard length) was significant $(\mathrm{P}<0.001)$, and there was no significant interaction between treatment and population $(\mathrm{P}>0.05)$.

Discriminant function analyses indicated significant differences in external body shape between treatments and populations. Our first DFA analysis classified fish by treatment; $85.3 \%$ of the original 211 fish were classified into the correct treatment (low vs. high oxygen) category (Wilks' $\lambda=$ $0.539, \mathrm{P}<0.001)$. Thus, all populations differed in external body shape metrics between treatments in so similar a man- ner, that most fish could be correctly classified into their rearing environment, regardless of population. Our second DFA predicted population of origin for each fish based on external body shape traits. This DFA was significant, but classified only $52.1 \%$ of the fishes into the correct population regardless of their rearing environment (Wilks' $\lambda=$ $0.835, \mathrm{P}<0.001)$, suggesting that environmental effects on external body shape are more strongly affected by the rearing environment than population of origin. Our third DFA predicted group based on the combination of population and treatment (null hypothesis of $\approx 1 / 6^{\text {th }}$ correct) and classified only $44.5 \%$ of the fish into the correct category (Wilks' $\lambda=$ $0.465, \mathrm{P}<0.001)$. 


\section{DISCUSSION}

\section{High Levels of Plasticity}

Most of the morphological traits we quantified in $P$. multicolor showed a remarkable amount of plasticity in response to the rearing environment; and for several traits, populations were similarly plastic. We found a phenotypically plastic response for most of the characters of the gills themselves, most of surrounding elements, and also all of the external body shape parameters. Gill size (e.g., total gill filament length, total gill surface area) was larger in fish raised under hypoxia. Evidence suggests that this is adaptive morphological plasticity. The induced morphological responses are of a nature one would predict to increase oxygen uptake capacity. A larger surface area allows for a more efficient oxygen transfer [57]; and for several species, populations from lowoxygen habitats are characterized by a larger total filament length and total gill surface area than populations from highoxygen sites [22, 34, 49, 58, 59].

One might anticipate a higher level of plasticity in morphological traits that have a limited number of functions such as gills (which serve as a surface for ion exchange and gas exchange); and thus may have fewer functional demands constraining shape changes. Indeed, other studies have demonstrated high levels of plasticity in gill traits in fishes, larval salamanders, and frogs [60-62]. There are apparently tradeoffs across different environments that favor the evolution and maintenance of plasticity. We found that adaptive change in gill size was accompanied by changes in the shape of the surrounding structural elements that may reduce the relative performance of a large-gilled fish in a welloxygenated environment. The larger hemibranch area implies that the total space taken up by the gills increased in response to development under hypoxia, and thus either the size of the surrounding elements should be smaller in compensation, or the external body shape should be expanded. Both seem to be the case. The reduction in the crosssectional area of the sternohyoideus muscle in fish raised under hypoxia suggests that larger gills are associated with lesser development of the $\mathrm{m}$. sternohyoideus, and thus potentially lower muscle performance. The external body shape of the fish was influenced by development under hypoxia, with potential consequences for the hydrodynamics of locomotory performance. Body depth, head width, and head length were all larger in fish reared under hypoxia, which again may reflect the increased space required for a larger gill apparatus. Interestingly, some of the surrounding structures showed an increase in length or depth, the m. geniohyoideus and the eye, respectively. These increases may be related to the increase in head length and depth that can accompany the increased size of the gills.

\section{Plasticity is not Larger in the Fluctuating Environment}

Contrary to our expectation, the plastic response to growth in alternative oxygen environments was, for several traits, as large in the population from the lake as in the populations of the more variable swamp and the highly variable river. There are at least three possible explanations for this. First, individuals that live in the Lake Kayanja ecotone may move during their lifetime to habitats that have less stable or lower oxygen content. In a study of the reproductive biology of fishes in the Kafunta swamp-river system, Welcomme
[63] found that the swamp served as an important nursery site for P. multicolor, but fish greater than $2.4 \mathrm{~cm}$ SL returned the river for a period of growth and maturation. In Lake Kayanja, it is possible that brooding females enter hypoxic areas of the marginal swamp to avoid predation, which would expose them to hypoxic stress. A second explanation may be that plasticity in these parameters is selectively advantageous in the lake because of fluctuations in other environmental parameters, e.g., food availability or variation in predator density. The gill arches form part of both the feeding and gill apparatus, and many muscles are involved in both food and oxygen uptake [22]. Several structures involved in predator detection also surround the gill apparatus (e.g., lateral line canals) and predator deterrence (e.g., open gape displays, and some muscles are involved in gill ventilation, filter feeding, and pharyngeal mastication). The third possibility is that the costs of plasticity in these traits are low, such that it is selectively advantageous to maintain plasticity for very rare perturbations of oxygen availability. A combination of explanations may be involved.

\section{Genetic Differentiation}

We found evidence for strong levels of environmentallyinduced plasticity in gill size, and all three populations showed similar levels of plasticity. In addition, there were differences among populations indicating a shift in the reaction norm in multivariate space. This indicates genetic differentiation in some gill parameters among populations, and probably reflects different selection pressures. Such differences in selection factors are likely to be found in environmental factors such as oxygen content, temperature, $\mathrm{pH}$, water current, turbidity, ionic content of the water, diet, and predator density. For example, overall gill size (as measured by our suite of traits) appeared to be smaller in laboratory raised F1s of swamp origin although the gill surface area was not. Interestingly, this suggests that in the swamp fish the space allocated to the gills is smaller than in the other two populations, while maintaining a similar respiratory surface. The relatively small overall gill size for a given gill respiratory surface probably poses less spatial constraints on surrounding elements. This is presumably an adaptation to the consistently low oxygen levels of the natural habitat, because in the field, the swamp fishes have, as expected, larger gills than those in the river and lake (Chapman and Galis, unpubl. data).

Most of the muscle traits showed no indication of genetic differentiation between populations. It may be important to preserve plasticity in the muscles as a way to respond to alternative oxygen environments. The benefit of thicker muscles when hypoxia is less severe may outweigh the potential cost of phenotypic plasticity. The size of the upper and lower pharyngeal jaws was smaller in fish of swamp origin than in fish of river and lake origin. These traits showed no plasticity in response to the oxygen treatments and the small size of the jaws may compensate for the larger gill size. It is also possible that the genetic differentiation of the pharyngeal jaws is entirely dictated by selection pressures related to food rather than oxygen availability and that pharyngeal jaws would exhibit developmental plasticity in response to different food treatments [64]. Clearly, for most traits, but in particular for the pharyngeal jaws, it is necessary to investigate the trade-off between feeding and oxygen uptake functions. 
In a parallel study we are now investigating this trade-off in the widespread cichlid Astatoreochromis alluaudi through a full-factorial rearing experiment where both food and oxygen are varied.

Most of the external body shape differences did not show support for genetic differentiation, except for body depth and epaxial depth. These traits exhibited a shift in the elevation of the reaction norm, but not a change in slope. For body depth, the shift occurred in the same direction as the plastic response, with smaller body depth in fish raised under normoxia and in fish from the high-oxygen lake environment. It is likely that greater body depth and larger head size may be a direct consequence of gill proliferation, though clearly other environmental features such as water flow may tug at these external body shape components as well.

\section{Possible Role of Genetic Assimilation}

We found evidence for differences among populations in the gill apparatus, surrounding structural elements, brain mass, and external body shape metrics. Presumably, because the experimental conditions were the same, these differences are genetic. For these traits (with the exception of the brain, for which we also found canalization, see below), we detected a change in mean trait values without a change in the level of plasticity in population, i.e. a shift in the norm of reaction. For example, gill size in field-collected fish was greater in swamp-dwelling $P$. multicolor than in lakedwelling fish, and a similar pattern was evident when fish were reared under low- or high-oxygen conditions in the lab. However, we also found evidence for population differences in the lab-reared fish. It is probable that genetic assimilation has contributed to mean differences in gill phenotype among populations, because there is an overlap in the norm of reactions for some gill metrics, and the swamp fishes presumably originally come from the river or lake environment. The maintenance of high levels of plasticity in these divergent populations may preserve the possibility for future responses to environmental changes and reflect to some degree the spatial and temporal heterogeneity within these habitats. It has been argued that plasticity may be useful to organisms in temporally and spatially heterogeneous environments [38, $39,54]$ or when gene flow is high among populations in divergent environments [48, 65].

Recently, the population structure of $P$. multicolor was examined from 10 sites in 4 regions of Uganda (including the three sites used in our rearing experiment) using mitochondrial DNA and microsatellites [48]; these results indicated high gene flow among populations. This suggests that selection against dispersers and their hybrids may be weak. The rearing experiment on $P$. multicolor under high- and low-oxygen indicates that genetic components to trait divergence exist among populations, and that this trait divergence seems to be adaptive. Thus, interestingly, in this system evolutionary divergence in ecologically important traits seems to occur in the face of high gene flow, which has also been shown for other studies in natural systems (e.g., [66-69]).

\section{Canalization of Brain Size in the Swamp}

Plasticity in brain size varied among populations, suggesting genetic variation in plasticity. Although we have not looked at the performance consequences of this brain size variation, there is evidence to suggest that this represents adaptive morphological plasticity. First, the induced morphological responses are in the direction that one would predict to decrease oxygen demand in a hypoxic environment. Second, similar inducible morphological responses were observed across the populations where brain mass showed treatment effects. Third, interdemic variation in brain mass between field populations (Chapman, Galis, Albert, unpubl. data) was in the same direction as that induced in the laboratory with smaller brain size in fish from a swamp-dwelling population than in the fish from the ecotonal waters of Lake Kayanja. The high oxygen use of the brain in teleost fishes [70] may imply selection for a smaller brain size in the swamp. The absence of plasticity in the swamp-dwelling population suggests that canalization and genetic assimilation has taken place. It is possible that the presence of plasticity may provide a too large risk in the swamps, because if the hypoxia would be less severe in the early life of fishes, the larger oxygen demand of a larger brain might lead to a severe hypoxic stress if aquatic oxygen decreases later on. The smaller variation in brain mass in the swamp fish is also in agreement with our hypothesis that the increased size of the gills may be at the expense of space available for the surrounding structures.

The small size of the brain may be less of a problem in the swamp than in the river and lake habitats, because of the absence of large predatory fishes in the swamp and the associated reduction in the need for predator detection and escape behaviour. There are indeed indications of an association between a small brain size and a low predation pressure in fishes [71, 72], and a growing body of evidence that hypoxic habitats may serve as a refuge for small fishes from large aquatic predators [73-76]. For example, in the Lake Victoria basin, swamps serve as both structural and low-oxygen refugia for hypoxia-tolerant fishes from the introduced aquatic predator, the Nile perch (Lates niloticus), a species intolerant of hypoxia [32, 43, 44, 76, 77].

\section{CONCLUSIONS}

Virtually all traits considered in our study of $P$. multicolor showed substantial plasticity in response to different dissolved oxygen levels in the laboratory. We also found evidence for population differences in the gill apparatus, structural elements surrounding the gills, brain mass, and external body shape metrics. For these traits (with the exception of the brain), we detected a change in mean trait values without a change in the level of plasticity in population i.e. a shift in the norm of reaction. Presumably the advantages of plasticity outweigh the costs for these traits. Fishes may well migrate between habitats with different oxygen content, and fluctuations take place not only in oxygen content but also in other relevant environmental parameters. The absence of plasticity in the brain size of F1s of swamp-dwelling origin suggests that genetic assimilation has taken place. It also suggests that there is very strong selection against a large brain size in the swamp, presumably because of its high oxygen demand. The high oxygen demand may both explain the small brain size and the absence of plasticity in the swamp. Even a slightly larger brain size may lead to too high an oxygen demand if oxygen levels reach below average values in the swamp. Recent studies of gene flow among $P$. multicolor populations [48] suggest that this genetic differ- 
entiation in ecologically important traits is occurring in the face of high gene flow emphasizing the importance of the selection for genetic differentiation. Plasticity may indeed allow individuals to survive when circumstances change and subsequently allow genetic changes to take place as a result of selection for a better adaptedness to the changed environment.

\section{ACKNOWLEDGEMENTS}

Funding for this study was provided from the National Science Foundation (IBN-0094393 to LC), the Wildlife Conservation Society (LC), the Natural Sciences and Engineering Research Council of Canada (Discovery Grant, LC), McGill University, the Canada Foundation for Innovation (LC), and the Canada Research Chair program (LC). Permission to conduct research in Uganda was acquired from the Uganda National Council for Science and Technology and Makerere University. We thank the following people for assistance with the care and maintenance of the experimental fish and assistance with morphological measures: Erin Reardon, Mayte Santamaria, Lu Wen-Chi Corrie, Guangjun Zhang, and Jaclyn Paterson. We also acknowledge the support of the field assistants of the Kibale Fish and Monkey Project in Uganda. Finally, we thank the following people for stimulating discussion that contributed to the development of the manuscript: Jacques van Alphen, Colleen Farmer, Raoul van Damme, and Thom DeWitt.

\section{REFERENCES}

[1] Baldwin, J.M. A new factor in evolution. Am. Nat., 1896, 30, 441451, 536-553.

[2] Osborn, H.F. Organic selection. Science, 1897a, 15, 583-587

[3] Osborn, H.F. The limits of organic selection. Am. Nat., 1897b, 31, 944-951.

[4] Morgan, C.L. Animal Behaviour, E. Arnold Press, London, 1900.

[5] Schmalhausen, I.I. Factors of Evolution. Blakiston, Philadelphia. PA., 1949

[6] Waddington, C.H. Genetic assimilation of an acquired character. Evolution, 1953, 7, 118-126.

[7] Waddington, C.H. Genetic assimilation of the Bithorax phenotype. Evolution, 1956, 10, 1-13.

[8] Matsuda, R. The evolutionary process in talitrid amphipods and salamanders in changing environments, with a discussion of "genetic assimilation" and some other evolutionary concepts. Can. J. Zool., 1982, 60, 733-749.

[9] Rollo C.D. Phenotypes, Their Epigenetics, Ecology and Evolution. Chapman and Hall, London, 1994.

[10] Hall, B.K. Organic selection, proximate environmental effects on the evolution of morphology and behaviour. Biol. Philos., 2001, 16, 215-237.

[11] Pigliucci, M.; Murren, C.J.; Schlichting, C.D. Phenotypic plasticity and evolution by genetic assimilation. J. Exp. Biol., 2006, 209, 2362-2367.

[12] Price, T.D.; Qvarnstrom, A.; Irwin, D.E. The role of phenotypic plasticity in driving genetic evolution. Proc. R. Soc. Lond. B., 2003, 270, 1433-1440.

[13] West-Eberhard, M.J. Developmental Plasticity and Evolution. Oxford University Press, Oxford, 2003.

[14] Schlichting, C.D. The role of phenotypic plasticity in diversification. In, Phenotypic Plasticity, Functional and Conceptual Approaches (ed. T.J. DeWitt and S.M. Scheiner), pp. 191-200. Oxford, Oxford University Press, 2004.

[15] Badyaev, A.V. Stress-induced variation in evolution, from behavioural plasticity to genetic assimilation. Proc. R. Soc. B., 2005, 272, 877-886.

[16] Ghalambor, C.K.; McKay, J.K.; Carroll, S.P.; Reznick, D.N. Adaptive versus non-adaptive phenotypic plasticity and the potential for contemporary adaptation in new environments. Funct. Ecol., 2007, $21,394-407$.
[17] Hinton, G.E.; Nowlan, S.J. How learning can guide evolution. Complex Syst., 1987, 1, 495-502.

[18] Borenstein, E.; Meilijson, I; and Ruppin, E. The effect of phenotypic plasticity on evolution in multipeaked fitness landscapes. $J$. Evol. Biol., 2006, 19, 1555-1570.

[19] Simpson, G.G. The Baldwin effect. Evolution, 1953, 7, 110-117.

[20] Hall B.K. Evolutionary Developmental Biology. Chapman and Hall, London, 1999.

[21] Levit, G.S. The roots of Evo-Devo in Russia, Is there a characteristic "Russian Tradition"? Theor. Biosci., 2007, 126, 131-148.

[22] Chapman, L.J.; Galis, F.; Shinn, J. Phenotypic plasticity and the possible role of genetic assimilation, Hypoxia-induced trade-offs in the morphological traits of an African cichlid. Ecol. Lett., 2000, 3, 387-393.

[23] Pigliucci, M.; Murren, C.J. Genetic assimilation and a possible evolutionary paradox, can macroevolution sometimes be so fast as to pass us by? Evolution, 2003, 57, 1455-1464.

[24] Williams G.C. Adaptation and Natural Selection. Princeton University Press, Princeton. N.J., 1966.

[25] Orr, H.A. Review, An evolutionary dead end? Science, 1999, 285, 343-344.

[26] de Jong, G. Evolution of phenotypic plasticity, patterns of plasticity and the emergence of ecotypes. New. Phytol., 2005, 166, 101-118.

[27] Behera, N.; Nanjundiah,V. Phenotypic plasticity can potentiate rapid evolutionary change. J. Theor. Biol., 2004, 226, 177-184.

[28] Egas, M.; Dieckmann, U.; Sabelis, M.W. Evolution restricts the coexistence of specialists and generalists, the role of trade-off structure. Am. Nat., 2004, 163, 518-531.

[29] Huey, R.B.; Hertz, P.E.; Sinervo, B. Behavioral drive versus behavioral inertia in evolution, A null model approach. Am. Nat., 2003, 161, 357-366.

[30] Ancel, L.W. Undermining the Baldwin expediting effect, Does phenotypic plasticity accelerate evolution? Theor. Popul. Biol., 2000, 58, 307-319.

[31] Chapman, L.J.; Chapman, C.A.; Brazeau, D.A.; McLaughlin, B.; Jordan, M. Papyrus swamps, hypoxia, and faunal diversification, variation among populations of Barbus neumayeri. J. Fish Biol., 1999, 54, 310-327.

[32] Chapman, L.J.; Chapman, C.A.; Nordlie, F.G.; Rosenberger, A.E. Physiological refugia, Swamps, hypoxia tolerance, and maintenance of fish biodiversity in the Lake Victoria Region. Comp. Biochem. Physiol., 2002a, 133 (A), 421-437.

[33] Chapman, L.J.; Nordlie, F.G.; Seifert, A. Respiratory oxygen consumption among groups of the African cichlid Pseudocrenilabrus multicolor victoriae subjected to different oxygen concentrations during development. J. Fish Biol., 2002b, 60, 242-251.

[34] Chapman, L.J.; DeWitt, T.J.; Tzaneva, A.; Paterson, J. Interdemic variation in the gill morphology of a eurytopic African cichlid. Proceedings of the $9^{\text {th }}$ International Symposium on Fish Physiology, Toxicology, and Water Quality. 2007, EPA/600/R-07/010, pp. 209-225

[35] Chapman, L.J. Morpho-physiological divergence across oxygen gradients in fishes. In Fish Respiration and the Environment.; Fernandes, M.N.; Rantin, F.T; Glass, M.L., Kapoor, B.G., Eds.; Science Publishers, Inc., Enfield, New Hampshire, 2007, pp. 14-39.

[36] Langerhans, R.B.; Chapman, L.J.; DeWitt, T.J. Complex phenotype-environment associations revealed in an East African cyprinid. J. Evol. Biol., 2007, 20, 1171-1181.

[37] Salzburger, W.; Meyer, A.; Baric, S.; Verheyen, R.; Sturmbauer, C. Phylogeny of the Lake Tanganyika cichlid species flock and its relationship to the Central and East African haplochromine cichlid fish faunas. Syst. Biol., 2005, 51, 113-135.

[38] Levins R. Theory of fitness in a heterogeneous environment. V. Optimal genetic systems. Genetics, 1965, 52, 891-904.

[39] Slatkin, M.; Lande, R. 1976. Niche width in a fluctuating environment-density independent model. Am. Nat., 1976, 110, 31-55

[40] Seegers, V L. Bemerkungen zur Gattung Pseudocrenilabrus. Die Aqu. U. Terr. Z., 1990, 43, 99-103.

[41] Greenwood P.H. 1965. The cichlid fishes of Lake Nabugabo, Uganda. Bull. Brit. Mus. Nat. Hist. (Zool.) 1965, 12, 315-357.

[42] Schierwater, B.; Mrowka, W. Factors influencing oxygen consumption in the cichlid fish Pseudocrenilabrus multicolor. Zool. Anz., 1987, 219, 305-312.

[43] Chapman, L.J.; Chapman, C.A.; Ogutu-Ohwayo, R.; Chandler, M.; Kaufman, L.; Keiter, A.E. Refugia for endangered fishes from an 
introduced predator in Lake Nabugabo, Uganda. Cons. Biol. 1996a, 10, 554-561.

[44] Chapman, L.J.; Chapman, C.A.; Chandler, M. Wetland ecotones as refugia for endangered fishes. Biol. Cons., 1996b, 78, 263-270.

[45] Rosenberger, A.E.; Chapman, L.J. Hypoxic wetland tributaries as faunal refugia from an introduced predator. Ecol. Freshwater Fish., 1999, 8, 22-34.

[46] Reardon, E.E.; Chapman, L.J. Reproductive seasonality in a swamp-locked African cichlid. Ecol. Freshwater Fish, 2008, 17, 20-29.

[47] Binning, S.A.; Chapman, L.J. Feeding ecology and diet overlap in riverine cichlids from western Uganda. Verh. Int. Verein. Limnol., 2008, 30(2), 283-286.

[48] Crispo, E.; Chapman, L.J. Population genetic structure across dissolved oxygen regimes in an African cichlid fish. Mol. Ecol., 2008, 17, 2134-2148.

[49] Timmerman, C.M.; Chapman, L.J. Hypoxia and interdemic variation in the sailfin molly (Poecilia latipinna). J. Fish Biol., 2004, 65, 635-650

[50] Muir, B.S.; Hughes, G.M. Gill dimensions for three species of tunny. J. Exp. Biol., 1969, 51, 271-285.

[51] Hughes, G.M. Measurement of gill area in fishes, Practices and problems. J. Mar. Biol. Assoc. UK, 1984, 64, 637-655.

[52] Albert, J.S.; Froese, R.; Bauchot, R.; Ito, H. Diversity of brain size in fishes, preliminary analysis of a database including 1174 species in 45 orders. In 5th Indo-Pacific Fish Conference Proceedings; Seret, B.; Sire, J.Y., Eds.; Societe Francaise d'Ichtyologie, Paris, France, 1999, pp. 647-656.

[53] Barel, C.D.N.; Witte, F.; M.J.P van Oijen, M.J.P. An introduction to the taxonomy and morphology of the haplochromine Cichlidae from Lake Victoria. Neth. J. Zool., 1977, 27, 333-389.

[54] Day, T.; Pritchard, J.; Schluter, D. A comparison of two sticklebacks. Evolution, 1994, 248, 1723-1734

[55] Reist, J.D. An empirical evaluation of several univariate methods that adjust for size variation in morphometric data. Can. J. Zool., 1985, 63, 1429-1439.

[56] Hendry, A.P.; Taylor, E.B. How much of the variation in adaptive divergence can be explained by gene flow, an evaluation using lake-stream stickleback pairs. Evolution, 2004, 58, 2319-2331.

[57] Hughes G.M.; Morgan, M. The structure of fish gills in relation to their respiratory function. Biol. Rev. Cambridge Phil. Soc., 1973, 48, 419-475.

[58] Galis F.; Barel C.D.N. 1980. Comparative functional morphology of the gills of African lacustrine Cichlidae (Pisces, Teleostei), An ecomorphological approach. Neth. J. Zool., 1980, 30, 392-430

[59] Chapman, L.J.; Hulen, K. Implications of hypoxia for the brain size and gill surface area of mormyrid fishes. J. Zool., 2001, 254, 461472.

[60] Bond, A.N. An analysis of the response of salamander gills to changes in the oxygen concentration of the medium. Develop. Biol., 1960, 2, 1-20.
[61] Burggren, W.W.; Mwalukoma, A. Respiration during chronic hypoxia and hyperoxia in larval and adult bullfrogs (Rana catesbeiana). I Morphological responses of lungs, skin and gills. J. Exp. Biol., 1983, 105, 191-203.

[62] Rutjes, H.A. Phenotypic responses to lifelong hypoxia in cichlids, Ph.D. dissertation, Leiden University, 2006.

[63] Welcomme, R.L. The biology and ecology of the fishes of a small tropical stream. J. Zool. Soc. (Lond.)., 1969, 158, 485-529.

[64] Hegrenes, S. Diet-induced phenotypic plasticity of feeding morphology in the orangespotted sunfish, Lepomis humilis. Ecol. Freshwater Fish, 2001, 10, 35-42.

[65] Sultan, S.E.; Spencer, H.G. Metapopulation structure favors plasticity over local adaptation. Am. Nat., 2002, 160, 271-283.

[66] Nice, C.C.; Fordyce, J.A.; Shapiro, A.M.; Ffrench-Constant, R. Lack of evidence for reproductive isolation among ecologically specialized lycaenid butterflies. Ecol. Ent., 2002, 27, 702-712.

[67] Emelianov, I. How adaptive is parasite species diversity? Int. J. Parasitol., 2007, 37, 851-860.

[68] Gavrilets, S.; Vose, A. Dynamic patterns of adaptive radiation. PNAS, 2005, 102, 18040-18045.

[69] Smith, T.B.; Calsbeek, R.; Wayne, R.K.; Holder, K.H.; Pires, D.; Bardeleben, C. Testing alternative mechanisms of evolutionary divergence in an African rain forest passerine bird. J. Evol. Biol., $\mathbf{2 0 0 5}, 18,257-268$

[70] Soengas J.L.; Aldegunde, M. Energy metabolism of fish brain. Comp. Biochem. Physiol. B. Biochem. Mol. Biol., 2002, 131, 27196.

[71] Bauchot, R.; Bauchot, M.-L.; Platel, R.; Ridet, J.-M. Brains of Hawaiian tropical fishes; brain size and evolution. Copeia, 1977 1977, 42-46.

[72] Bauchot, R.; Randall, J.E.; Ridet, J.-M.; Bauchot, M.-L. Encephalization in tropical teleost fishes and comparison with their mode of life. J. Hirnforsch, 1989, 30, 645-669.

[73] Robb, T.; Abrahams, M.V. Variation in tolerance to hypoxia in a predator and prey species, an ecological advantage of being small. J. Fish Biol., 2003, 62, 1067-1081.

[74] Sloman, K.A.; Wood, C.M.; Scott, G.R.; Wood, S.; Kajiumura, M.; Johannsson, O.E.; Almeida-Val, V.M.F.; Val, D. Tribute to R.G. Boutilier. The effect of size on the physiological and behavoural responses of oscar, Astronotus ocellatus, to hypoxia. J. Exp. Biol., 2006, 209, 1197-1205.

[75] McNeil, D.L.; Closs, G.P. Behavioural responses of a south-east Australian floodplain fish community to gradual hypoxia. Freshwater Biol., 2007, 52, 412-420.

[76] Chapman, L.J.; Chapman, C.A.; Witte, F.; Kaufman, L.; Balirwa, J. Biodiversity Conservation in African Inland Waters, Lessons of the Lake Victoria Basin. Verh. Int. Verein. Limnol., 2008, 30(1),16-34.

[77] Schofield, P.J.; Chapman, L.J. 1999. Interactions between Nile perch, Lates niloticus, and other fishes in Lake Nabugabo, Uganda. Envir. Biol. Fish, 1999, 55, 343-358

(C) Chapman et al.; Licensee Bentham Open

This is an open access article licensed under the terms of the Creative Commons Attribution Non-Commercial License (http://creativecommons.org/licenses/by-nc/3.0/) which permits unrestricted, non-commercial use, distribution and reproduction in any medium, provided the work is properly cited. 